\title{
INDIVIDUAL AND MEDICAL CHARACTERISTICS OF ADULTS PRE- SENTING TO AN URBAN EMERGENCY DEPARTMENT IN GHANA
}

\author{
R. A. OTENG ${ }^{1,5}$, L.K. WHITESIDE ${ }^{3}$, S. D. ROMINSKI ${ }^{4}$, J. H. AMUASI ${ }^{5,6}$, P. M. CARTER ${ }^{1,2}$, P. \\ DONKOR $^{7}$ and R. CUNNINGHAM ${ }^{1,2}$ \\ ${ }^{1}$ University of Michigan, Department of Emergency Medicine, Ann Arbor, MI, USA, ${ }^{2}$ University of Michigan, \\ Injury Center, Ann Arbor, MI, USA, ${ }^{3}$ University of Washington, Division of Emergency Medicine, Seattle, \\ WA, USA, ${ }^{4}$ Global REACH, University of Michigan Medical School, Ann Arbor, MI, USA, ${ }^{5}$ Komfo Anokye \\ Teaching Hospital, Kumasi, Ghana, ${ }^{6}$ Kumasi Center for Collaborative Research in Tropical Medicine, \\ ${ }^{7}$ Kwame Nkrumah University of Science and Technology, Kumasi, Ghana
}

DOI: $h t t p: / / d x$.doi.org/10.4314/gmj.v49i3.2

Corresponding Author: Dr. Rockefeller Oteng

Conflict of Interest: None declared

\section{SUMMARY}

Background: The aims of this study were to characterize the patients seeking acute care for injury and noninjury complaints in an urban Emergency Department in Ghana in order to 1) inform the curriculum of the newly developed Emergency Medicine resident training program 2) improve treatment processes, and 3) direct future community-wide injury prevention policies

Study Design: A prospective cross-sectional survey of patients 18 years or older seeking care in an urban Accident and Emergency Center (AEC) was conducted between 7/13/2009 and 7/30/2009. Questionnaires were administered by trained research staff and each survey took 10-15 minutes to complete. Patients were asked questions regarding demographics, overall health and chief complaint.

Results: 254 patients were included in the sample. Participants' chief complaints were classified as either medical or injury-related. Approximately one third $(38 \%)$ of patients presented with injuries and $62 \%$ presented for medical complaints. The most common injury at presentation was due to a road traffic injury, followed by falls and assault/fight. The most common medical presentation was abdominal pain followed by difficulty breathing and fainting/ blackout. Only 13\% arrived to AEC by ambulance and $51 \%$ were unable to ambulate at the time of presentation.

Conclusion: Approximately one-third of non-fatal adult visits were for acute injury. Future research should focus on developing surveillance systems for both medical and trauma patients. Physicians that are specifically trained to manage both the acutely injured patient and the medical patient will serve this population well given the variety of patients that seek care at the AEC.
Email: roteng@med.umich.edu

Keywords: Emergency Medicine, Injury, Surveillance, Ghana, Characteristics

\section{INTRODUCTION}

In line with the health-related Millennium Development Goals, the global health community has traditionally focused on the improvement in in maternal and child health indicators and the control of infectious diseases, including HIV/AIDS, malaria and tuberculosis. ${ }^{1}$ These disease-specific or vertical efforts to health improvement, versus a more integrated, or horizontal, approach, have not sufficiently strengthened health systems. ${ }^{2,3}$

Subsequently there is a relative deficit in the ability of developing country health systems to respond to and manage acute patient presentations and mass injury events. ${ }^{4}$ Implementing and improving emergency medicine specialties within existing healthcare systems in countries in the midst of the epidemiologic transition, ${ }^{5}$ where the burden of disease is shifting from infectious to chronic and human-influenced disease processes, is crucial.

According to the World Health Organization (WHO), about 5.8 million people die each year as a result of injuries, accounting for $10 \%$ of the world's deaths; $32 \%$ more than the number of fatalities that result from malaria, tuberculosis, and HIV/AIDS combined. ${ }^{6}$ For developing countries, injury contributes a larger proportion to cause of death and years of life lost. ${ }^{7}$ It is imperative that health services adapt to the increasing burden of injury. One such country is Ghana.

Comprehensive surveillance systems are expected to assist in effectively understanding the burden of both injury and acute medical presentations. In Ghana, no such surveillance systems are currently fully functional to allow researchers and policy makers to follow trends 
over time. For example, only a small percentage of pedestrian injuries are included in police statistics; not all injured persons receive formal medical care; and several other vital statistics are inadequately captured. A further limitation to the utility of these data is that it does not include data from acute care health facilities such as emergency departments. ${ }^{8}$

The aims of this study were to characterize the patients seeking acute care for injury and non-injury complaints an urban emergency department of a teaching hospital in West Africa in order to inform the curriculum of the nascent Emergency Medicine (EM) resident training program, to improve treatment processes, and to direct future community-wide injury prevention policies.

\section{MATERIALS AND METHODS}

\section{Setting}

This study was conducted in the Accident and Emergency Center (AEC) at Komfo Anokye Teaching Hospital (KATH) in Kumasi, Ghana. This facility provides injury and emergency care to the 1.4 million residents of Kumasi and the surrounding Ashanti region (an additional 3 million people). ${ }^{9}$ The Ashanti region accounts for nearly one-fifth of Ghana's total population; Kumasi is the region's capital and largest city. KATH's EM department records an average of 27,000 visits per year and functions as the highest-level referral center for the northern two-thirds of the country.

In 2008, the University of Michigan, the Kwame Nkrumah University of Science and Technology (KNUST) and KATH began working together to develop a residency-training program in emergency medicine. Simultaneously, this Collaborative is working to produce a highly functional, well-staffed emergency department at the KATH AEC. All study procedures were approved and conducted in compliance with the University of Michigan Institutional Review Board for Human Subjects guidelines and the Committee on $\mathrm{Hu}-$ man Research, Publications and Ethics at KATH and KNUST.

\section{Survey content and administration}

Screened participants included all patients 18 years or older seeking cares in the KATH AEC who was able to give informed consent. Trained Research Assistants (RA) administered questionnaires while patients were waiting to be triaged, waiting for care while in the AEC after triage, or after the physician had initiated care. Each survey took 10-15 minutes to complete. Exclusion criteria included inability to converse in Akan or if translation was not available, altered mental status, need for acute care, or if the patient expired before the survey was completed.
Questions regarding demographic information, overall health status and the individual components that informed a socioeconomic index were drawn from the Ghana National Survey. Prior to beginning the study, the survey tools were pre-tested in the KATH polyclinic waiting room to ensure the questions were locally specific, appropriate, and not burdensome. Based on findings from this exercise and feedback from the Research and Development unit at KATH, the final study was revised.

The questionnaire asked subjects about characteristics related to the current visit, including chief complaint, transportation method(s), reason for choosing the AEC for care, and patient mobility. At the time of the survey, it was not standard protocol at the AEC to record vital signs during triage, and documentation of disposition following ED visit was not being systematically tracked. Therefore data on vital signs at presentation or final ED diagnosis is not available to be used in assessing severity of illness or injury. The RA's assessment of mobility and mental status was recorded as a proxy measure of severity.

Research staff was trained on the classification of injury using the ICD- 9 E-code.(10) Injury visits were classified as intentional (E950-E969) or unintentional (E800-E869, E880-E929) by RAs based on the patient interview at time of visit.

\section{Data analysis}

Data were analyzed using SPSS version 17. (SPSS Company, Chicago, IL) Descriptive statistics were calculated for demographics and visit characteristics. A bivariate analysis compared patients presenting with medical complaints to those presenting with injuryrelated complaints.

\section{RESULTS}

\section{Characteristics of the sample}

The study sample included 254 patients (Table 1). Participants' chief complaints were classified as either medical-related or injury-related. $38 \%$ of the sample presented with injury and $62 \%$ with medical complaints. The mean age was 46 years (sd 19.5) and 59\% were male. Regarding the current visit, 56\% reached the AEC by car and over one-third traveled for more than one hour to get there.

Nearly half were ambulatory at presentation, over twothirds had visited the facility prior to the current visit, and over half reported their past-year health as very good. Overall, $71 \%$ of the sample noted some type of health insurance at initial presentation. 
While $55 \%$ of the patients who sought care due to an injured patients had insurance coverage injury complaint had health insurance, $75 \%$ of the non-

Table 1 Demographics, visit characteristics, and analysis of factors associated with injury versus non-injury presentation $(\mathrm{n}=254)$

\begin{tabular}{|c|c|c|c|c|}
\hline & $\begin{array}{l}\text { All patients } \\
\mathrm{n}=254 \\
\mathrm{n}(\%) / \mathrm{m}(\mathrm{sd})\end{array}$ & $\begin{array}{l}\text { Injured patients } \\
\mathrm{n}=96(38 \%) \\
\mathrm{n}(\%) / \mathrm{m}(\mathrm{sd})\end{array}$ & $\begin{array}{l}\text { Non-injured } \\
\text { tients } \\
\mathrm{n}=158(62 \%) \\
\mathrm{n}(\%) / \mathrm{m}(\mathrm{sd})\end{array}$ & OR and $95 \% \mathrm{CI}$ \\
\hline \multicolumn{5}{|l|}{ Demographics } \\
\hline Male** & $149(58.7)$ & $64(66.7)$ & $85(53.8)$ & $0.58(0.34,0.99)$ \\
\hline Age (years)** & $46.0(19.5)$ & $40.0(17.2)$ & $50.0(20.0)$ & $\mathrm{n} / \mathrm{a}$ \\
\hline $18-24$ & $34(13.4)$ & $20(20.8)$ & $14(8.9)$ & REFERENCE \\
\hline $25-34$ & $57(22.4)$ & $24(25.0)$ & $33(20.9)$ & $0.51(0.22,1.21)$ \\
\hline $35-44$ & $40(15.7)$ & $19(19.8)$ & $21(13.3)$ & $0.63(0.25,1.59)$ \\
\hline $45-54$ & $43(16.9)$ & $17(17.7)$ & $26(16.5)$ & $0.46(0.18,1.14)$ \\
\hline $55-64 *$ & $26(10.2)$ & $6(6.3)$ & $20(12.7)$ & $0.21(0.07,0.66)$ \\
\hline$\geq 65^{*}$ & $54(21.3)$ & $10(10.4)$ & $44(27.8)$ & $0.16(0.06,0.42)$ \\
\hline Married & $136(53.5)$ & $47(49.0)$ & $89(56.3)$ & $0.74(0.45,1.24)$ \\
\hline \multicolumn{5}{|l|}{ Education } \\
\hline Completed secondary school & $75(30.2)$ & $26(27.4)$ & $49(32.0)$ & $0.80(0.45,1.41)^{\mathrm{a}}$ \\
\hline Completed some school (primary or middle) & $114(46.0)$ & $46(48.4)$ & $68(44.4)$ & \\
\hline No school & $59(23.8)$ & $23(24.2)$ & $36(23.5)$ & \\
\hline Employed out of the house* & $198(78.6)$ & $83(88.3)$ & $115(72.8)$ & $2.82(1.37,5.80)$ \\
\hline \multicolumn{5}{|l|}{ Past-year health } \\
\hline Very good* & $123(51.5)$ & $65(69.9)$ & $58(39.7)$ & $4.17(2.27,7.65)^{b}$ \\
\hline Good & $25(10.5)$ & $10(10.8)$ & $15(10.3)$ & \\
\hline Moderate, bad or very bad & $91(38.0)$ & $18(19.4)$ & $73(50.0)$ & \\
\hline Insured (national or other)* & $175(71.1)$ & $51(53.1)$ & $124(82.7)$ & $0.24(0.13,0.43)$ \\
\hline \multicolumn{5}{|l|}{ Characteristics of ED acute care visit } \\
\hline \multicolumn{5}{|l|}{ Mode of Transportation to A\&E } \\
\hline Ambulance & $33(13.2)$ & $18(18.8)$ & $15(9.7)^{2}$ & $2.14(1.02,4.48)$ \\
\hline Private car & $66(26.4)$ & $26(27.1)$ & $40(26.0)$ & \\
\hline Public transportation & $140(56.0)$ & $43(44.8)$ & $97(63.0)$ & \\
\hline Other & $11(4.4)$ & $9(9.4)$ & $2(1.3)$ & \\
\hline Traveled 1 hour or more & $89(38.2)$ & $35(40.7)$ & $54(36.7)$ & $1.18(0.68,2.04)$ \\
\hline \multicolumn{5}{|l|}{ Mobility } \\
\hline Required a stretcher, walking with help & $128(51.0)$ & $45(47.4)$ & $83(53.2)$ & $0.79(0.47,1.31)$ \\
\hline Ambulatory & $123(49.0)$ & $50(52.6)$ & $73(46.8)$ & REFERENCE \\
\hline Sought care for problem prior to today & $168(67.5)$ & $52(54.7)$ & $116(75.3)^{1}$ & $0.40(0.23,0.68)$ \\
\hline Visited facility prior to today & $117(49.4)$ & $29(31.5)$ & $88(60.7)^{1}$ & $0.30(0.17,0.52)$ \\
\hline \multicolumn{5}{|l|}{ Reason facility was chosen } \\
\hline Referred & $126(51.6)$ & $48(52.2)$ & $78(51.3)$ & $1.03(0.62,1.74)$ \\
\hline Used before and had good experience & $8(3.3)$ & $2(2.2)$ & $6(3.9)$ & $0.54(0.11,2.74)$ \\
\hline Friend/relative used before and had good experience & $10(4.1)$ & $3(3.3)$ & $7(4.6)$ & $0.70(0.18,2.77)$ \\
\hline Facility has best staff & $67(27.5)$ & $19(20.7)$ & $48(31.6)$ & $0.56(0.31,1.04)$ \\
\hline Closest to home & $37(15.1)$ & $18(19.6)$ & $19(12.4)$ & $1.72(0.85,3.47)$ \\
\hline
\end{tabular}

$* \mathrm{p}<0.01,{ }^{* *} \mathrm{p}<0.05$

${ }^{\mathrm{a}} \mathrm{OR}$ compares completed secondary school to did not complete secondary school

${ }^{b} \mathrm{OR}$ compares very good/good to moderate, bad, or very bad self-reported health status (Table 1)

The most common injury at presentation (Table 2) was due to a road traffic injury (35\%), followed by a fall $(22 \%)$ and assault/fight (14\%). Of those injured $16 \%$ were intentional injuries, including 7 assaults, 4 lacerations and 3 penetrating injuries. Nearly one third of all injuries occurred at home and $20 \%$ while at work.

Of those reporting injuries, the majority of participants noted injuries that included the extremities (88\%), followed by chest $(17 \%)$ and head $(12 \%)$ injuries. Note that more than one injury region was reported by $n=29$ (31\%) injured patients (see Figure 1). Of the eleven patients reporting head injuries, $72.7 \%(n=8)$ were noted to be ambulatory on presentation. Of the 27 injuries that were reported to be caused by another person, slightly more than half $(52 \%)$ were caused by a stranger while 3 (11\%) were reported as self-harm.

The most common medical presentation (Figure 2) was abdominal pain $(26 \%)$ followed by difficulty breathing $(7.0 \%)$ and fainting / blackout (7\%). 
Table 2 Characteristics of Injury $(n=96)$

\begin{tabular}{|l|c|}
\hline Cause of Injury & N (\%) \\
\hline Unintentional injury & $81(84.0)$ \\
\hline Road Traffic Injury & $34(35.4)$ \\
\hline Car Crash & $20(20.8)$ \\
\hline Pedestrian Injury & $6(6.3)$ \\
\hline Motorcycle & $7(7.3)$ \\
\hline Pedal Bike/Bicycle & $1(1.0)$ \\
\hline Fall & $21(21.9)$ \\
\hline Burn & $3(3.1)$ \\
\hline Poisoning/Overdose & $1(1.0)$ \\
\hline Cut Laceration not related to fight & $9(9.3)$ \\
\hline Other/unknown & $15(15.6)$ \\
\hline Burn & $3(3.1)$ \\
\hline Poisoning/Overdose & $1(1.0)$ \\
\hline Intentional injury & $\mathbf{1 5 ( 1 6 )}$ \\
\hline Assault/Fight & $13(14.1)$ \\
\hline Injury occurred on date of visit & $36(40.4)$ \\
\hline Where did injury occur & \\
\hline Home & $29(31.9)$ \\
\hline Work & $18(19.8)$ \\
\hline Street & $44(48.4)$ \\
\hline Injury caused by stranger & $14(51.9)$ \\
\hline & \\
\hline
\end{tabular}

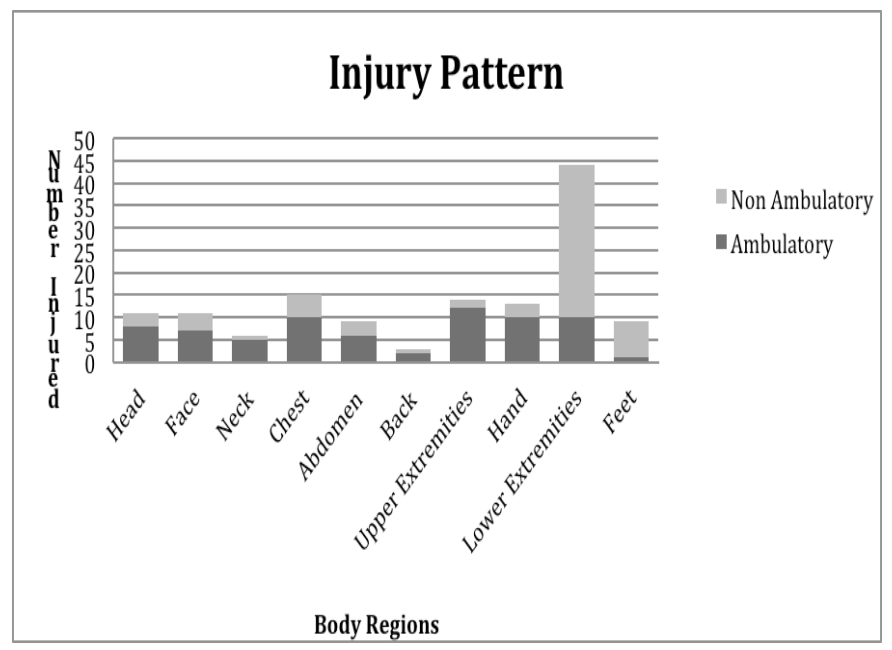

Figure 1 Body regions injured in ambulatory and nonambulatory patients on presentation

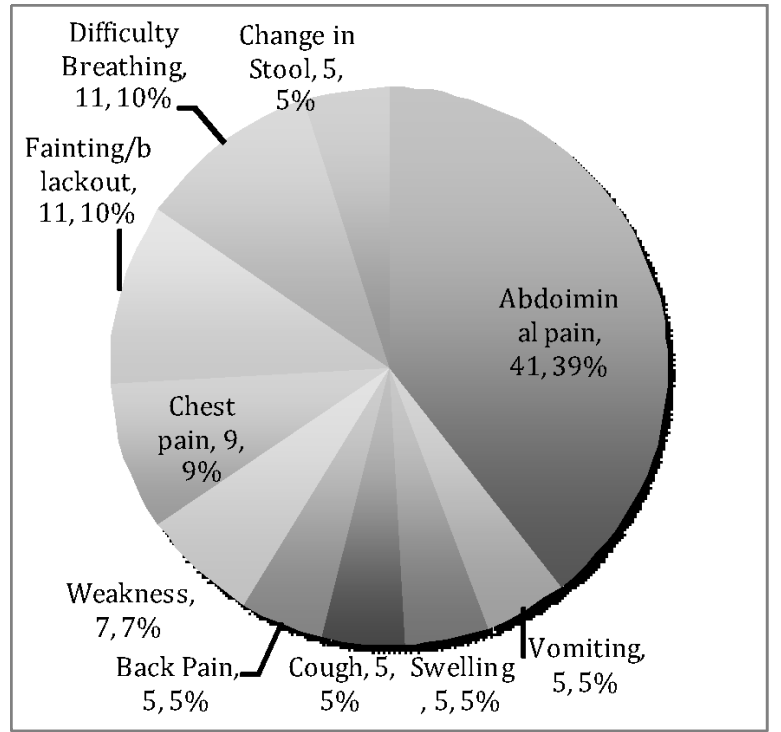

Figure 2 Chief complaints for the non-injured patients $\left(\mathrm{n}=158^{*}\right)$

*Shows data for chief complaints with $\mathrm{n} \geq 5$. Data not shown: blood in urine, dizziness, fever, slurred speech $(\mathrm{n}=4)$; bleeding, body aches, headache, pain, pain with urination $(\mathrm{n}=3)$; diarrhea, seizures/spell, wound - infection suspected $(n=2)$; blood in cough, difficulty swallowing, eye complaint, fatigues, gynecological-related complaint, jaundice, mental state, bite $(n=1)$. Also not shown: other $(n=9)$.

\section{DISCUSSION}

In this study, approximately one third of patients presented for injuries, which is similar to that in the US. ${ }^{11}$ The importance of injury in contributing to the global burden of disease in low-income countries is in part due to the increased use of motorized vehicles and rapid industrialization. However, data on acute medical care including care of the injured not requiring hospitalization is lacking.

The proportion of injuries due to road traffic injuries in this analysis was similar to the proportion of injuries related to motor vehicle injuries in the U.S. and Canada (35.4\% versus 30\%), according to the National Trauma Databank 2010 report. ${ }^{12}$ It is lower, however, than that found in a hospital-based study of injured patients in Malawi13 (43.4\%). The higher proportion of road traffic-related injuries in the Malawi study may be because that study included children as well as adults.

A 2007 report by Ghana's Ministry of Transportation indicates substantial increases in motor vehicle crashes (MVCs) and crash fatalities, with a corresponding increase in the vehicle population. ${ }^{14}$ These data from the ED at KATH may assist national and local efforts to improve all aspects of road safety, from public education to policy measures, as well as improving the delivery of acute care for victims of road traffic injuries. 
Falls were second most common in this study $(21.9 \%)$ followed by assaults. According to the WHO, falls are the second leading cause of unintentional injury deaths worldwide. ${ }^{15}$ In the U.S. and Canada, falls are responsible for the greatest number of injury-related deaths. ${ }^{12}$ Prevention strategies recommended by the WHO include education, training, and research and risk reduction activities.

In the bivariate analysis, patients presenting with injury were more likely to be employed than those presenting with medical complaints; injured patients also characterized themselves as healthier and were less likely to be over 55 years of age compared to those presenting with medical complaints. This may be associated with the fact that nearly $20 \%$ of injuries occurred in the workplace, and young healthy people are more likely to be employed.

Injured patients were more likely to arrive via ambulance, which may be a crude measure of injury severity as ambulances are used almost solely for hospital transfers in this region of Ghana. Although a measure of severity of injury was beyond the scope of this work, $12 \%$ of injuries were to the head region, which may translate into significant morbidity. Additionally, more research is needed to understand the associated mental health risk factors of the $3 \%$ of injuries were noted to be related to self-harm.

Emergency medical transport and trauma systems are in the nascent stage of development in many Low and Middle Income Countries (LMIC). In Ghana, an EMS service was initiated with 10 donated ambulances in 2003 when the Accra soccer stadium collapsed killing hundreds of people. Previous work by Mock and colleagues showed that a significant percentage of patients in Kumasi with severe trauma-related injuries die before transport to the hospital. ${ }^{16}$ In this sample, only $13 \%$ of patients were transported by ambulance. Increasing emergency medical transport services along with improved pre-hospital and care of injured patients may improve outcomes and decrease secondary disability.

This study, the first to characterize the adult population seeking acute care at an ED in urban Ghana, highlights the importance of a curriculum for acute medical providers that focuses on trauma and care of the acutely injured. Previous work done in South Africa highlights the need to assess patient characteristics seeking care to inform a newly developed Emergency Medicine residency curriculum. ${ }^{17}$ Access to increased training and adherence to standard trauma protocols may reduce disability and mortality even without increased financial resources to the site.

As stated above, this study noted that the incidence and contribution of trauma to acute presentations was similar in Kumasi as in the US and Canada. However, as noted by Mock et al, (1998) the associated morbidity and mortality with these traumatic injuries is much greater in LMIC's. One particular reason may be the lack of an organized team approach to these patients. A multidisciplinary approach to the severely injured patient that would include surgery, trauma, orthopaedics, pediatrics and trained emergency providers is important to improve the care of these patients, and is currently lacking in Ghana.

Although injury mechanisms were well represented in the patient population, the majority presented with acute medical complaints concerns. The high percentage of patients seeking care for non-injury complaints that needed a stretcher or assistance walking is an indicator of the severity of illness with which this subset of patients presented. These patients sought care for their presenting complaints prior to the day on which data were collected at a much higher rate than the injuryrelated presentations and visited a facility prior to the day data were collected. To further understand this phenomenon, future research should consider if this represents acute exacerbation of chronic disease among this population.

To further address the needs of the presenting patient population, systems changes such as the introduction of a triage system, implemented by nurses, based on severity of illness or injury could improve outcomes. In South Africa, this very system has been shown to decrease wait times for critically ill patients 18 . In summary, the patient population that is presenting to this Accident and Emergency Centre highlight the need for increased resources and training in the care of acutely ill and injured patients.

\section{CONCLUSIONS}

This study showed that more than one-third of nonfatal adult visits to an urban ED in a LMIC were for acute injury. It also displays the significant numbers of patients who present with acute medical complaints. Emergency physicians, nurses and support staff that are specifically trained to manage both the acutely injured patient and the critically ill medical patient would serve this population well. Future work includes establishing ongoing surveillance of acute injury and medical presentations in collaboration with local and national agencies on injury prevention and early recognition of acute illness, particularly those related to motor vehicle crashes and falls. 


\section{ACKNOWLEDGEMENTS}

We would like to thank Pat Bergeron for administrative assistance and Stephanie Harrison for statistical support. Finally, special thanks are owed to the patients and medical staff at Komfo Anokye Teaching Hospital Accident and Emergency Center for their support of this project.

\section{REFERENCES}

1. Macfarlane S, Racelis M, Muli-Musiime F. Public health in developing countries. Lancet. 2000 Sep 2;356(9232):841-6. PubMed PMID: 11022943.

2. Mills A. Mass campaigns versus general health services: what have we learnt in 40 years about vertical versus horizontal approaches? Bull. World Health Organization. 2005 Apr;83(4):315-6. PubMed PMID: 15868024. Pubmed Central PMCID: 2626210.

3. Atun R, de Jongh, T., Secci, F., Ohiri, K., Adeyi, O. A systematic review of the evidence on integration of targeted health interventions into health systems. Health Policy Plan. 2010 Jan;25(1):1-14. PubMed PMID: 19959485.

4. Razzak JA, Kellermann AL. Emergency medical care in developing countries: is it worthwhile? Bull World Health Org 2002;80(11):900-5. PubMed PMID: 12481213. Pubmed Central PMCID: 2567674.

5. Omran AR. The epidemiologic transition. A theory of the epidemiology of population change. The Milbank Memorial Fund quarterly 1971 Oct;49(4):509-38. PubMed PMID: 5155251.

6. WHO World Health Organization. Global Burden of Disease. WHO 2004.

7. Krug EG, Sharma GK, Lozano R. The global burden of injuries. American Journal of Public Health 2000 Apr;90(4):523-6. PubMed PMID: 10754963. Pubmed Central PMCID: 1446200. Epub 2001/02/07. eng.

8. London J, Mock, C., Abantanga, F. A., Quansah, R. E., Boateng, K. A. Using mortuary statistics in the development of an injury surveillance system in Ghana. Bull World Health Org 2002;80(5):35764. PubMed PMID: 12077610. Pubmed Central PMCID: 2567797

9. Ghana Statistical Service. National Data Archive Accra, Ghana: Ministry of Finance and Economic Planning; 2011 [cited 2011 September 9, 2010].
10. National Center for Health Statistics \& U.S. Health Care Financing Administration. The International Classification of Diseases, 9th Revision, Clinical Modification: ICD-9-CM. Washington, D.C.: US Department of Health and Human Services, Public Health Service, 2000.

11. Centers for Disease Control and Prevention. National Hospital Ambulatory Medical Care Survey: 2007 Emergency Department Survey. Atlanta, GA: U.S. Department of Health and Human Services, 2010 August 6, 2010. Report No.: 26.

12. American College of Surgeons. National Trauma Data Bank 2010 Annual Report 2010. Available from:

http://www.facs.org/trauma/ntdb/pdf/ntdbannualre port2010.pdf.

13. Samuel JC, Akinkuotu, A., Villaveces, A., Charles, A. G., Lee, C. N., Hoffman, I. F., Miller, W. C., Baloyi, P., Hoffman, M., Brown, L. B.Muyco, A. P. Epidemiology of injuries at a tertiary care center in Malawi. World J Surg. 2009 Sep;33(9):1836-41. PubMed PMID: 19597877. Pubmed Central PMCID: 3290404.

14. Republic of Ghana MoT. National Road Safety Commission 2007 Annual Report 2007 [March 25, 2011]. Available from: http://www.nrsc.gov.gh/publications/doc/2007\%20 annual\%20report\%20dav\%20adom\%20ruddy.pdf.

15. World Health Organization. Falls: WHO; 2010 [March 22, 2011]. Available from: http://www.who.int/mediacentre/factsheets/fs344/e $\mathrm{n} /$ index.html.

16. Mock CN, Amegashie J, Asiamah G. Epidemiology of alcohol impaired driving in an African nations 42nd Annual Proceedings. Des Plaines, IL AAAM: 1998.

17. Cohen KL, Wallis LA. Is the current South African emergency medicine curriculum fit for purpose? An emergency medicine practice analysis. Emergency medicine journal 2011;28(11):955-8. PubMed PMID: 20972227.

18. Bruijns SR, Wallis LA, Burch VC. A prospective evaluation of the Cape triage score in the emergency department of an urban public hospital in South Africa. Emergency medicine journal. 2008 Jul;25(7):398-402. PubMed PMID: 18573947. 